\title{
La difusión de los estereotipos de género a través de las TIC: La mujer en el vídeo musical
}

institucional.us.es/ambitos/

\section{Jennifer Rodríguez-López}

Universidad de Huelva

jennifer.rodriguez@dedu.uhu.es

English Version: The broadcasting of gender stereotypes through the ICT: The woman in the music videos

\begin{abstract}
Resumen
Los estereotipos de género son generalizaciones en torno al rol que se presupone a hombres y mujeres. Las tecnologías de la información y la comunicación facilitan la difusión de estas ideas que son transmitidas a través de medios como el vídeo

musical. Mediante una metodología de análisis basada en el examen de determinados aspectos objetivos relativos a la imagen así como a los valores y los sentimientos que se desprenden de cada clip, se realiza un estudio de diferentes vídeos musicales centrándose en los estereotipos relacionados con el rol de la
\end{abstract} mujer.

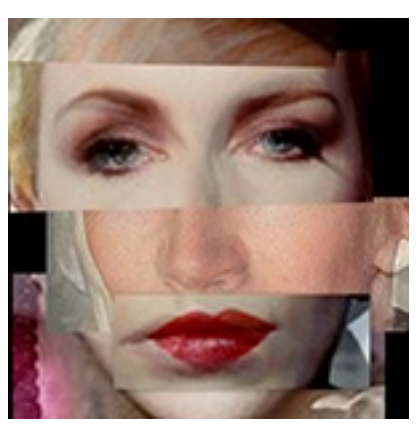

Palabras clave

Estereotipo, género, TIC, vídeo musical.

Abstract

Gender stereotypes are generalizations about the role that assume men and women. The information and communication technologies facilitate the broadcasting of these stereotypes that are transmitted through mass media such as music video. The methodology is based on the exam to the objectives aspects relative to the image and the values and the feelings that emerge from each clip. The result is a study of different music videos focused on the analysis of stereotypes concerning the role of women.

\section{Keywords}

Stereotype, Gender, ICT, Music Video.

\section{LOS ESTEREOTIPOS DE GÉNERO Y LA INFLUENCIA DE LAS TIC EN LA SOCIEDAD ACTUAL}

Los estereotipos en general, y aquellos centrados en las diferencias de género en particular, invaden los medios de comunicación actualmente. Formatos como el vídeo musical se enfocan principalmente hacia un target adolescente, consumidores mayoritarios de estos productos audiovisuales. Por ello, se subraya la necesidad de un análisis de los estereotipos de género en los videoclips con la finalidad de ahondar en la alfabetización mediática de los usuarios y espectadores. En este artículo se examinan los prejuicios asociados al género y los roles desarrollados por las mujeres en distintos vídeos musicales que representan tipologías diferentes de cada uno de ellos.

Así, se definen los estereotipos como aquellas generalizaciones sobre distintos grupos sociales que simplifican la realidad, favoreciendo el arraigamiento de determinados roles sociales. Se encuentran en todos los ámbitos de la sociedad, creando ideas rígidas sobre el género, la raza, el estatus económico o el nivel educativo, entre otros. Este estudio se centra en aquellos relacionados con el género, definido por Colás y Villaciervos (2007: 37) como «una representación cultural, que contiene ideas, prejuicios, valores, interpretaciones, normas, deberes, mandatos y prohibiciones sobre la vida de las mujeres y de los hombres». De esta forma, inciden en la construcción de las identidades de ambos géneros y en los roles de estos desempeñados tanto de forma 
individual como colectiva. En este sentido, estos autores afirman que «las personas se convierten en hombres y mujeres en función del aprendizaje de representaciones culturales de género que rigen, no sólo, su constitución genérica, sino también, el carácter de las relaciones que, unos y otras, mantienen en diferentes esferas sociales (en ámbitos como la familia, la escuela, el grupo desiguales, etc.). Así, el género, como sistema cultural, provee de referentes culturales que son reconocidos y asumidos por las personas» (Colás \& Villaciervos, 2007: 38). Como se desprende de lo anteriormente expuesto, los estereotipos sociales poseen una función primordial en la creación de identidades y de pertenencia a un grupo así como en la comprensión de la realidad de una manera simplificada, coherente y ordenada. Por su parte, Berganza y Del-Hoyo (2006: 162) sostienen que «dos son las características básicas de los estereotipos: la representación simplificada de la realidad y la resistencia al cambio». Según las autoras, se trata de imágenes simplificadas de la realidad que pertenecen al imaginario colectivo y que son fácilmente identificables. Sin embargo, tienen también un carácter negativo cuando estas ideas se convierten en estancos rígidos y evolucionan hacia los prejuicios como conjunto de juicios y creencias de carácter negativo con relación a un grupo social (González-Gabaldón, 1999: 83). Por ello, los prejuicios vinculados con el género hacen referencia a ideas preconcebidas vinculadas con las características asignadas a los roles del hombre y de la mujer.

De este modo, el papel masculino asumido a través de los estereotipos contiene rasgos como la estabilidad emocional, la agresividad, la valentía, la intelectualidad o la eficacia, entre otros. Mientras que la mujer se define de forma estereotipada por la intuición, la ternura, la sumisión y la frivolidad, entre otros aspectos. PérezGauli $(2000,18)$ aprecia cómo la figura humana se presenta en los medios, sobre todo en la publicidad, siempre del mismo modo, lo que favorece que los espectadores identifiquen ese patrón como el ideal. Se trata del siguiente modelo: occidental, blanco, joven y mesomorfo (atlético) en el caso de los hombres y etnomorfo (delgado) en el caso de las mujeres. Este mismo autor afirma que el modelo de belleza único creado por los medios de comunicación masivos hacen hincapié en lo irreal, lo artificial y lo digital y apunta que «este modelo publicitario se ha impuesto como un canon universal de belleza, que tratan de imitar muchos de los hombres y mujeres de los diferentes países industrializados del mundo y que condiciona el modo en el que miramos y juzgamos a los demás». Los estereotipos son compartidos por la sociedad de manera inconsciente, atribuyendo distintas actitudes a hombres y mujeres por pertenecer a distintos géneros. Se produce una relación muy estrecha entre estereotipo, prejuicio y discriminación. Los últimos conceptos poseen un cariz negativo, ya que el prejuicio deriva en la discriminación, es decir, la falta de conducta de igualdad en el tratamiento otorgado a las personas en virtud de su pertenencia a un grupo social determinado sobre el que existe un prejuicio. Por su parte, el estereotipo se torna importante en la socialización del individuo, interviniendo en la formación de su identidad social, en el fomento de su inclusión en un grupo de referencia y la identificación y aceptación del mismo.

Las tecnologías de la información y la comunicación (TIC) han evolucionado a gran ritmo y su uso ha transformado todos los ámbitos de la sociedad. Esta realidad ha sido subrayada por la UNESCO (2004: 17) al afirmar que «en la última década, las nuevas herramientas tecnológicas de la información y la comunicación han producido un cambio profundo en la manera en que los individuos se comunican e interactúan en el ámbito de los negocios, y han provocado cambios significativos en la industria, la agricultura, la medicina, el comercio, la ingeniería y otros campos». Se evidencia cómo el empleo de estas tecnologías ha llegado a los ámbitos no profesionales, siendo utilizadas por todo tipo de usuarios, convirtiéndose en una herramienta de uso doméstico.

Es por ello que la digitalización de los contenidos abre nuevas posibilidades a las TIC, tal y como apunta Campos-Freire (2012: 300) entre las que destacan «mayores posibilidades de interactividad, accesibilidad, disminución de costes de creación y producción, aumento de la facilidad de almacenaje y promoción, velocidad de distribución, mejora de las relaciones con las demandas y combinación de las economías de escala con las de red y de club». Este proceso de digitalización, añade valores a la producción cultural como la interactividad y mejora la accesibilidad, la difusión y la administración de los contenidos multimedia, así como reduce considerablemente los costes de creación, producción y promoción de los productos, lo que se traduce en un acceso para los usuarios a un precio muy bajo. Sin embargo, también existen consecuencias negativas como la piratería, los contenidos clónicos o la fragmentación y la difusión de los estereotipos de género, entre otros (Campos-Freire, 2012: 301). Por esto, se subraya la necesidad de disminuir las consecuencias negativas de la difusión de los contenidos multimedia a través de las TIC anteriormente descritas mediante la alfabetización 
mediática tal y como afirman Belmonte y Guillamón (2008: 115) ya que «se requiere una educación audiovisual que les alfabetice en los medios y en sus lenguajes, pero enfatizando su importancia como sujetos receptores que construyen su identidad, en parte, a través de las representaciones televisivas», tratando de concienciar a los usuarios sobre el uso y el tratamiento correcto de los contenidos.

En cuanto a la construcción de las identidades individuales y colectivas así como la creación y propagación de los estereotipos, estas autoras sostienen que «los medios de comunicación han adquirido en las últimas décadas un importante papel como agente socializador, ayudando a construir identidades y contribuyendo, de esta manera, a establecer los sistemas simbólicos a través de los discursos y del imaginario que transmiten» (Belmonte \& Guillamón, 2008: 116), por lo que atribuyen a los productos audiovisuales y a los medios de comunicación un rol activo en la difusión de los estereotipos así como modelos de conducta que influyen en la sociedad mediante un aparato retórico y seductor.

De esta forma, las TIC fomentan la difusión de valores y estereotipos entre los que se encuentran aquellos relacionados con el género y con el papel de la mujer en los medios. La presencia total de estas tecnologías en la sociedad actual potencia la introducción de ideas estereotipadas y prejuicios en los individuos. Por sus características se propicia la implantación de las mismas de una forma sencilla y casi desapercibida para los usuarios, ya que se trata de instrumentos ya asumidos como naturales en una sociedad rodeada de tecnología y medios de comunicación de masas en la que prima lo audiovisual.

\section{EL VÍDEO MUSICAL COMO VEHÍCULO DE DIFUSIÓN DE VALORES Y ESTEREOTIPOS}

El vídeo musical se define en este artículo como un producto audiovisual y promocional de la industria discográfica que toma influencias directas del lenguaje cinematográfico, publicitario y de las vanguardias artísticas. Fruto de la era postmoderna, supone la traducción en códigos visuales de una canción mediante el uso de novedosas e impactantes técnicas digitales que pretenden seducir al espectador y que forjan una imagen de marca alrededor del cantante.

Una de las primeras delimitaciones del concepto de videoclip es la aportada por Durá (1988: 12) en la que es denominado como «una serie de realizaciones audiovisuales destinadas a fomentar el consumo musical entre los sectores juveniles de la sociedad». Este autor alude, como rasgo principal, a su naturaleza audiovisual y a su esencia promocional, en particular, dirigido a un target de público joven. En este sentido, Sedeño (2008: 751) concluye que los videoclips «son producciones audiovisuales desarrolladas por el mercado de la música, una industria que genera no pocos beneficios, y dirigidas fundamentalmente a los jóvenes», incidiendo en las mismas ideas que Durá dos décadas antes. Así, se evidencia la intención del vídeo musical en relación con la industria cultural al ser un producto de las compañías discográficas, sirviendo de estrategia publicitaria para la promoción de la música en su forma material. Leguizamón (2001: 254) afirma que «es un producto insertado en una estrategia de comercialización que responde a la potenciación de la obra musical a través de una obra visual que se ensambla con la forma musical». Asimismo, mantiene relación con otras industrias culturales como el cine, la televisión, la publicidad, el arte, la vídeo-creación, la fotografía, el cómic y la danza, entre otros.

Por su parte, Sánchez-López (2002: 566) determina que se trata de «una creación audiovisual de vocación cinematográfica surgida al calor del mundo contemporáneo y el vendaval massmediático, un testigo

excepcional de las expectativas e inquietudes de las subculturas y tribus urbanas, un reclamo consumista para la juventud en su calidad de soporte publicitario de los productos de la industria discográfica y un vehículo para la autoafirmación y/o difusión y/o propaganda de los respectivos grupos y movimientos que alientan e inspiran su génesis al identificarse con una declaración de intenciones, un código 'ético' y una forma determinada de vivir, comportarse y pensar, siendo también consecuentemente un documento antropológico polivalente, contradictorio y versátil». Es una de las definiciones del videoclip más completa ya que en ella refleja la influencia del cine y la publicidad y su naturaleza de difusión masiva como mecanismo de promoción de la industria discográfica, en relación con los colectivos sociales actuales y con el afán consumista.

De modo más sintético, y de vuelta a la definición de Durá, Roncero-Palomar (2008: 20) afirma que «un vídeo musical es una obra audiovisual, de intención fundamentalmente promocional, ya sea de la banda/artista o del 
tema musical, de 3 o 4 minutos de duración, en la que, por lo general, se presenta a una banda/artista interpretando el tema, a veces acompañada de imágenes con valor narrativo propio y otras, con un valor poético». En ella aparecen los elementos comunes sobre la condición audiovisual del clip y su objetivo comercial, así como se apela a su duración como elemento diferenciador con otros formatos y el valor añadido basado en la narración y en la expresión estética.

Como formato publicitario, producto de las industrias culturales y género difundido masivamente, el vídeo musical utiliza los estereotipos como un recurso que permite la identificación de determinadas ideas de forma rápida y sencilla, ya que debido a su breve duración precisa de herramientas que le ayuden en la condensación y rápida asimilación de las mismas.

\section{METODOLOGÍA}

La metodología aplicada sobre los distintos vídeos musicales analizados se basa en la propuesta realizada por Aguaded y Pérez (1995: 65) centrada en el estudio de los estereotipos en la publicidad y aplicable a otros formatos. Estos autores pretenden «desvelar los mecanismos persuasivos y los clichés estereotipados que la publicidad transmite» a través de una lectura crítica. En su metodológica se tienen en cuenta para el análisis los elementos de la comunicación, abordando el contenido y la finalidad del mensaje, el canal, el emisor, los receptores, los recursos gráficos y lingüísticos y el contexto. Así mismo también se examinan las estrategias de persuasión, el impacto en los consumidores y los modelos de conducta que este tipo de mensajes reflejan, entre otros aspectos.

El primer paso en el método planteado por estos autores es la lectura de las imágenes, interpretando el contenido y las intenciones de los mensajes publicitarios. Dicha lectura debe realizarse de una forma crítica, es decir, «analizando los contenidos, las intenciones y los valores sociales que el emisor de la imagen ha querido transmitir, mediante unos canales y formas específicas» (Aguaded \& Pérez, 1995: 66). El método consta de cinco partes siendo la primera de ellas la elaboración de una ficha técnica en la que se tendrán en cuenta el tipo de imagen, el género, el soporte, el formato, la superficie, el tipo de plano y de angulación y los elementos predominantes.

En la parte dedicada a la lectura objetiva de las imágenes se analizan los elementos compositivos y la distribución del formato, centrándose en aspectos como el uso del color, el tipo de plano y las angulaciones, entre otros. Se trata de distinguir los elementos que componen la imagen, sin ningún tipo de valoración, descomponiendo su estructura para un mejor análisis de las partes a través de la descripción.

La siguiente tarea se corresponde con el estudio de las características principales de la imagen, examinadas a través de distintos binomios: originalidad y redundancia, iconicidad y abstracción, monosemia y polisemia, simplicidad y complejidad, denotación y connotación, tratando de hallar las figuras retóricas que operan en la imagen publicitaria.

Así, la fase de lectura subjetiva complementa el análisis a través del estudio del grado de significación, las connotaciones emocionales y valorativas de la imagen y las ideologías y patrones de conducta reflejados.

El modelo aportado trata de valorar los elementos dispuestos en los mensajes publicitarios, en particular, y de la imagen, en general, a partir de una lectura objetiva complementada con una visión subjetiva en la que el analista interpreta los significados subyacentes, así como las características de la imagen y su relación con el registro verbal. La finalidad de esta propuesta es la alfabetización en los medios de los alumnos a través de una experiencia directa con el análisis audiovisual que se vería complementado con la realización y producción de sus propios mensajes publicitarios.

Este método de análisis es adaptado en este artículo para el estudio de los estereotipos de género en el vídeo musical por lo que dicho examen de cada uno de ellos se realiza en base a la siguiente estructura: una introducción, en la que se exponen datos acerca del intérprete y el año de la canción, el director del clip o el álbum en el que se incluye, entre otros. Tras el concepto del clip y el resumen del argumento del mismo, se 
realiza la lectura objetiva basada en los rasgos constitutivos de este como los escenarios y personajes presentes, el número y el tipo de planos y el montaje asociado a la banda sonora. El siguiente paso es la lectura subjetiva centrada en el análisis de los sentimientos y valores reflejados en el videoclip así como los estereotipos generales y particularmente enfocados hacia la diferencia de género y el papel de la mujer. De esta forma, se plantea un análisis global tanto de las características de la imagen como de los estereotipos fomentados por el clip. La elección de los vídeos musicales analizados a continuación se justifica por su valor paradigmático, su actualidad y la gran difusión de los mismos tanto en internet como en los canales temáticos dedicados al videoclip, y cuyo alcance se evidencia en la posesión de numerosas nominaciones y premios de cada uno de ellos.

\section{ANÁLISIS DE LOS ESTEREOTIPOS DE GÉNERO EN EL VÍDEO MUSICAL}

\subsection{La mujer objeto: Don't Stop the Party, Pitbull}

Este vídeo musical de 2012 fue dirigido por David Rosseau y rodado en Miami. La canción de base está interpretada por Pitbull en colaboración con el DJ TJR y compuesta por Armando Pérez, Bigram Zayas, TJR y Frederick "Toots" Hibbert, para el séptimo álbum del cantante. La letra combina inglés y español, este último principalmente en el estribillo. El registro verbal se corresponde con el visual, ensalzando la actitud festiva y la diversión, así como la relación con la figura femenina presente también en la letra.

Se trata de una canción enfocada hacia la época estival lo que influye en el estilo del clip y en su estética, basada en los estereotipos de la canción ligera en la que se muestran imágenes al ritmo de esta con carácter alegre y optimista. En él se observa al cantante rodeado de un séquito compuesto por numerosas y bellas mujeres mientras se encuentran en distintos ambientes de fiesta y diversión. Por ello, no se observan rasgos originales ni novedosos en el uso de técnicas visuales sino que prima la sencillez y la simplicidad del concepto desarrollado, es decir, el clip se centra en la exhibición de una actitud festiva en la que la ingesta de alcohol, la música, el baile y la sensualidad son los protagonistas. Se muestra a los personajes divirtiéndose en distintos escenarios de tipo lujoso lo que subraya la idea de la letra de la canción.

Por este sentido opulento, las distintas escenas se realizan en tres escenarios principales: por un lado, aquellas ejecutadas en una enorme casa con piscina en la que aparecen planos tanto en el interior de la misma como en el exterior -principalmente de la piscina. El otro escenario es la cubierta y en el interior de un barco en el que los personajes inciden en una actitud de diversión y de libertad sexual. Por último, se muestra una estancia interior, un dormitorio, en la que el cantante aparece realizando su actuación dirigiéndose a la cámara mientras un pequeño grupo de mujeres retozan semidesnudas en una cama situada al fondo. Estas secuencias se producen tanto en escenarios diurnos como nocturnos.

Este videoclip se compone de 215 planos entre los que abundan aquellos de tipo general que tratan de recoger la totalidad del ambiente representado así como la ubicación espacial de las escenas; junto a planos medios que se centran tanto en el cantante como en las mujeres que lo acompañan. Del mismo modo se aprecian primeros planos que enfatizan las actitudes de los personajes y que concentran la atención sobre algún detalle presente en escena. Estos planosse suceden con transiciones por corte de forma rápida acorde con el ritmo de la canción. Las secuencias en los distintos escenarios se alternan conforme a las distintas partes melódicas. Otros efectos sintácticos son la partición de la pantalla en cuatro partes iguales en las que se presentas diferentes escenas, así como secuencias en blanco y negro y otras registradas con cámara nocturna combinadas con el color de la mayoría de estas.

La sencillez caracteriza este videoclip en el que se presenta a los cantantes en distintos escenarios en una actitud totalmente festiva. Así, la performance es la absoluta protagonista con la ausencia de narración vinculada al tono de la canción y al tono estival de la misma. Ello refuerza una lectura cómoda y fácil por parte del espectador.

Los sentimientos principales que se desprenden tanto de la letra de la canción como de las imágenes asociadas a esta son los de alegría, diversión, fiesta, despreocupación, desahogo económico, lujo, prestigio, exclusividad, 
alto nivel de vida, placer, etc., es decir, se presenta a través de los personajes y los escenarios una actitud hedonista.

Los estereotipos mostrados se basan en el lujo y en los beneficios de la clase alta cuyos ingresos económicos les permiten disfrutar de una serie de actividades de tipo lúdico como las expuestas en el vídeo musical: fiestas en lujosos barcos y en grandes casas en ciudades en las que la exclusividad, la moda y el dinero son valores en alza y en las que la fiesta se realiza en multitud que beben, comen y bailan sin cesar.

Por otra parte, aparecen estereotipos relacionados con el canon de belleza establecido ya que aparecen mujeres jóvenes y bellas en actitud sensual y jovial poblando las diferentes escenas, un recurso típico en este tipo de vídeo musical.

Respecto al rol de la mujer, esta se encuentra representada de forma accesoria al papel recreado por la figura masculina. Mientras el hombre -principalmente el cantante- aparece con una posición protagonista, la mujer se muestra casi como una masa que conforma la fiesta y que carece de entidad e identidad propia. Los personajes femeninos que pueblan las diferentes escenas se presentan casi desnudas, en actitudes de despreocupación sexual y casi lasciva, de forma festiva e interactuando con el cantante como si se tratase de una figura de poder que ellas desean y veneran.

Así, las bailarinas que actúan como extras y que refuerzan el carácter festivo y sensual de las imágenes se divide a su vez en dos grupos: el primero compuesto por cuatro mujeres que acompañan al cantante en numerosas escenas como la de la habitación y la del barco entre otras, y que disfrutan de mayor protagonismo que el resto; y un segundo grupo en el que aparece un sinnúmero de mujeres que componen la fiesta y que interactúan con el resto de personajes en escena manteniendo una actitud marcadamente sexual.

Casi como un principio general de los estereotipos visuales del vídeo musical, se muestra un canon de belleza del cuerpo femenino ajustado a unos patrones muy definidos y que impiden que la mayoría de mujeres se sienta identificada con el modelo de mujer representado. Se trata de mujeres jóvenes, delgadas, altas, de piernas largas, busto y glúteos muy generosos -y en la mayoría de los casos fruto de operaciones de cirugía estética-, piel sin imperfecciones, labios gruesos, etc. Su actitud frente a la cámara y juntos a los personajes masculinos es desinhibida y muy descarada en lo relativo a la sexualidad.

La escena más significativa y representativa de lo anteriormente expuesto es aquella en la que el cantante aparece en una habitación en la que se encuentra una cama con cuatro chicas semidesnudas, con ropa interior sugerente, que mantienen una actitud sexual y seductora frente a la cámara y con el cantante, quien aparece totalmente vestido y con una disposición de superioridad sobre las chicas. Así, el ambiente general de este vídeo musical insiste en esta idea, así como en la representación de la fiesta, la diversión y la relajación propia del verano, mostrando una postura nihilista y hedonista de la vida, y en particular de la sexualidad.

Por ello, la relación entre hombres y mujeres no se presenta de forma igualitaria y equilibrada sino que se insiste en la perpetuación de los prejuicios y estereotipos de género a través de los medios de comunicación de masas.

\subsection{La mujer-cuerpo: Blurred Lines, Robin Thicke}

Blurred Lines forma parte del disco homónimo de Robin Thicke lanzado en 2013 como sexto álbum en la carrera del cantante. La canción es una colaboración de Thicke con el rapero T.l. y Pharrell Williams, productor de la misma, teniendo gran acogida por crítica y público. El vídeo musical, dirigido por Diane Martel, cuenta con dos versiones, ya que la primera fue censurada por su contenido sexual. En la segunda versión, las modelos que acompañan a los cantantes durante su actuación aparecen vestidas de manera escasa mientras que en el clip original se mostraban casi desnudas.

El concepto desarrollado guarda relación con el sentido de la letra, de tipo ligero y con numerosas referencias sexuales. La simplicidad caracteriza el argumento y la escenografía del mismo, ya que se desarrolla en un único escenario de color blanco y neutro en el que los personajes interactúan con diferentes elementos. Los personajes presentes, quienes realmente pueblan la escena enriqueciéndola, son los tres cantantes junto a tres 
modelos que visten de forma similar con conjuntos en blanco y plástico transparente. Así, entre los elementos con los que estos interactúan aparece un sinfín de objetos destacando una oveja, un banjo, una cama, heno, un taburete, un coche de juguete, un guante de dedo gigante, billetes, un cepillo del pelo, un perro disecado, una bicicleta, un helado, unos dados gigantes, un mechero de gran tamaño, una inyección enorme, una máscara con unos ojos pintados y unos globos plateados en la que se lee la frase: «Robin Thicke has a big dick». Dichos accesorios facilitan el dinamismo de las escenas equilibrando la neutralidad del fondo y del vestuario. Otros recursos refuerzan esa sensación como los movimientos de los personajes femeninos o la inserción de grafismos en ambas versiones como «\#TICKE» y «\#BLURREDLINES» en alusión a los hashtag utilizados en redes sociales como Twitter. Estos códigos gráficos ocupan la totalidad de la pantalla y se presentan en grandes letras mayúsculas y de color rojo, atrayendo la atención del espectador de forma ineludible.

Respecto al número y al tipo de plano, ambas versiones cuentan con 130 planos entre los que se alternan planos generales que presentan a la totalidad de personajes en la escena así como planos medios y primeros planos de los rostros de los mismos. Estos últimos se utilizan para captar las expresiones de los existentes así como la actuación de los cantantes, atrayendo la atención del espectador. Se alternan sintácticamente creando un juego entre planos generales y primeros planos, así como planos medios que presentan a los personajes desde la cintura. La transición entre planos se realiza de forma limpia, es decir, no existe ningún mecanismo de transición entre los mismos sino que se realizan los cortes al cambiar de plano. Se trata por ello, de un montaje sencillo y pausado en armonía con el resto de elementos que caracteriza este clip.

Los sentimientos y valores que se desprenden del clip guardan relación con la desinhibición, la libertad sexual y el placer vinculado a la fiesta y la celebración como muestran los personajes presentes en escena. Su actitud es alegre y despreocupada y parecen divertidos. Estos sentimientos se transmiten a través del uso de determinados objetos con los que los personajes interactúan entre ellos y en la versión censurada con la presencia de bebidas alcohólicas -aparecen bebiendo Rémy Martin haciendo uso de la técnica del product placement-, lo que enfatiza el sentido festivo de la canción y del vídeo musical.

Los estereotipos representados en este vídeo musical se centran en el rol de los personajes, claramente diferenciados en dos grupos: los cantantes y las modelos. En cuanto a los cantantes, estos manifiestan estereotipos relacionados con su papel dominante de hombre y de seductor. Esta afirmación tiene su reflejo en el vestuario elegido, ya que aparecen vestidos de forma elegante al estilo dandy, con traje de chaqueta negro, camisa blanca, zapatos de vestir negros y gafas de sol. Así, se muestran en actitudes tradicionalmente adjudicadas al papel masculino como fumar, beber alcohol, etc. Por su parte, las modelos aparecen prácticamente desnudas lo que aumenta la dicotomía entre los personajes. El papel de las chicas es marcadamente sexual y se muestran en una actitud levemente infantil, enfatizando el estereotipo de guapa y tonta. La diferencia de papeles se percibe también en el color del vestuario elegido para cada grupo, ya que ellos aparecen vestidos en colores oscuros, contrastando con el fondo, mientras que las chicas se presentan con ropa de color blanco por lo que no destacan sobre el fondo del mismo color.

El rol femenino reflejado en este clip guarda relación con la letra de la misma, de alto contenido machista en la que la mujer es tratada como un ser inferior creado para satisfacer las necesidades sexuales del hombre. Esto se desprende del sentido genérico de la letra y se ejemplifica en frases como «tried to domesticate you but you're an animal», "you're far from plastic» (aludiendo a las operaciones de cirugía estética para el aumento de pecho), «you the hottest bitch in this place» o «had a bitch, but she ain't bad as you». Así, en ambas versiones, y en especial en la censurada, la atención se centra sobre el cuerpo femenino como reclamo y mecanismo de seducción, mientras que los personajes masculinos permanecen estáticos en la escena ya que son ellas quienes desfilan y muestran un rol más activo.

Este vídeo musical supone un paso atrás en la lucha por la igualdad de género al tratar la imagen femenina como un accesorio del hombre con el que este juega. No se observa un tratamiento igualitario para ambos sexos sino que se percibe la superioridad de los personajes masculinos sobre los femeninos, quienes poseen un valor secundario y un papel sumiso y de servidumbre sexual. Se concluye cómo la mujer continúa ejerciendo como objeto de seducción con el fin de atraer al espectador en un ámbito audiovisual que cuenta actualmente con numerosas técnicas enfocadas hacia la misma finalidad. Sin embargo, el cuerpo femenino sigue siendo un reclamo efectivo lo que subraya su poder en la iconosfera contemporánea. 


\subsection{La mujer liberada: Dirrty, Christina Aguilera}

Este vídeo musical dirigido por David Lachapelle en 2002 muestra un estereotipo de los clips al mismo tiempo que los transfigura: por una parte, aparecen hombres musculosos y mujeres en actitud sexy, lo que incide en los tópicos del género Pop. Sin embargo, por otra parte, la cantante adopta un rol masculino -escupe, pelea, va en moto- tratando de recuperar una posición de la que la mujer ha sido excluida.

La canción fue escrita por Christina Aguilera, el rapero Redman y el compositor Rockwilder para el álbum Stripped. La letra de la misma, muy explícita, se caracteriza por su contenido sexual, lo que entronca con el vídeo musical, muy provocativo y casi obsceno. Se crea una relación entre la diversión festiva, el sexo y la lucha libre.

Así, la motivación principal de este vídeo musical es la expresión de una actitud de libertad sexual muy explícita para el espectador que actúe como mecanismo de seducción que facilite el recuerdo del producto del clip, asociando esta imagen a la cantante. Por ello, el clip supuso una revolución desde su lanzamiento debido a la actitud excesivamente sexual de la cantante, quien se había presentado de una forma mucho más dulce y recatada en sus discos anteriores. Se trataba así de captar la atención del público sobre la nueva imagen de la cantante. Su estética resultó polémica por su alto contenido sexual y fue censurado al mismo tiempo que fue elegido como el vídeo musical más sexy de la historia, siendo uno de los más vistos en plataformas como YouTube y VEVO. En la actualidad, las actitudes sexuales son frecuentes en los vídeos musicales, a las que se recurre como un mecanismo de impacto y seducción para el espectador. Sin embargo, el videoclip analizado supuso una ruptura con la estética conservadora de otras artistas de moda como Britney Spears, quien también rompió con esa imagen aniñada en sus posteriores clips.

El concepto desarrollado en este vídeo musical es de gran legibilidad y fácil descodificación por parte del espectador, ya que la representación es muy simple: la joven y atractiva cantante realiza su actuación en un escenario oscuro y masificado ejecutando coreografías de alto contenido sexual junto a un grupo de bailarinas. Sin embargo, el elevado número de personajes en escena y de extras que la pueblan dificulta el visionado de cada uno de estos elementos, algunos de ellos perdidos entre la masa, por lo que se requiere de varios pases del clip para apreciar todos ellos de forma particular y en el entramado del vídeo musical. Este hecho es enfatizado por el montaje rápido y el cambio de plano caracterizado por la velocidad.

Las escenas se registran en lo que parece una sucia nave de tipo industrial y de gran tamaño en la que las acciones se realizan sobre un cuadrilátero de lucha libre, lo que parecen unas duchas comunes y unos largos pasillos que recorre el cantante Redman. Se trata de decorados interiores en los que se realizan las coreografías y otras acciones como lucha de barro y la escenificación de un combate entre la cantante y una joven enmascarada.

El clip se estructura en 174 planos entre los que se encuentran planos generales en los que se presentan la totalidad de la escena y de la multitud de personajes que la pueblan. También aparecen planos detalle de la boca de la cantante mientras ejecuta la verbalización de la canción, incidiendo en el sentido sexual de los labios. Los planos se acercan para mostrar la coreografía realizada por el grupo de bailarinas junto a la cantante, hasta llegar al primer plano del rostro de esta mientras realiza la performance.El montaje de los planos se realiza acorde al ritmo de la canción, con cambios rápidos de plano y transiciones sin corte. Se realizan zooms para abrir el plano desde el rostro de la cantante hacia la totalidad de la escena junto al resto de personajes, así como el movimiento inverso. En la escena del pasillo, se ejecuta un travelling hacia atrás que acompaña al cantante Redman mientras lo recorre. En el momento en el que ambos cantantes interactúan, los planos de sus rostros se van intercambiando desde cada una de sus ubicaciones, así como distintas escenas en las que aparecen otros personajes realizando distintos bailes y movimientos.

Los sentimientos provocados se asocian a dos sensaciones: deseo sexual y suciedad. El título de la canción alude a este doble sentido de la suciedad relacionada con la higiene y la suciedad vinculada con la liberación sexual. Ambas actitudes se ven reflejadas en los personajes y en el escenario, de aspecto mugriento y oxidado, combinado con los movimientos y gestos de la cantante y las bailarinas de tipo sexual. La provocación sexual es el sentimiento principal dirigido a la captación del espectador hasta el final del vídeo musical, su perduración 
en la memoria y en el tiempo, y la asociación de esta imagen sexual y transgresora con la cantante.

Al tratarse de un vídeo musical cuya esencia se basa en la provocación y en la transgresión, unidas a una presentación de una imagen sexual de la cantante, los estereotipos mostrados se relacionan con estas ideas. Por ello, aparecen elementos vinculados con la actitud fuerte de la cantante como la gran moto y la escena de lucha, así como metáforas de la liberación sexual como la cárcel.

Analizado en su contexto y también en relación a la actualidad de los medios de comunicación de masas este vídeo musical supone una evolución del papel de la mujer en los clips, quienes se habían mantenido en un papel secundario como bailarinas junto al cantante, o en un papel protagonista pero manteniendo una actitud discreta. Christina Aguilera irrumpió en la escena clip con una apariencia provocativa, sexual y alejada de la dulzura propia de los inicios de su carrera.

El canon de belleza representado se adecúa a los estereotipos fomentados por la prensa y la televisión como principales medios de comunicación de masas. Se basa en un prototipo de mujer joven, excesivamente delgada, sin apenas curvas, musculosa y sin grasa pero femenina y sexual. Además fomenta la liberación social y sexual de la mujer aunque quizás de una forma excesiva y polémica. El cuerpo masculino es representado de acuerdo a los estereotipos sociales en los que se prescribe con una complexión esbelta, musculada, sin grasa, hombres jóvenes y fuertes, muy viriles y masculinos, bronceados, con aspecto sano, deportivos, etc.

El sexo y el cuerpo femenino es utilizado como un recurso para promocionar el propio vídeo musical y a la artista a través de una exhibición descarada de la actitud sexual de forma abierta, liberada y desinhibida.

Se exhibe una actitud altamente sexual por parte de mujeres, quienes juegan en el clip un rol protagonista y activo, en contraposición al estereotipo clásico del cantante masculino rodeado de mujeres objeto que únicamente pueblan la escena de forma accesoria, como un objeto más y un mecanismo de seducción vacío y vacuo.

\subsection{La mujer rebelada: Hard Out Here, Lily Allen}

Esta canción fue escrita en 2013 por la cantante Lily Allen en colaboración con Greg Kurstin para su disco Sheezus. La letra de la misma gira en torno a las presiones sobre la imagen corporal y la misoginia infligida por las compañías discográficas, en particular, y por la industria del entretenimiento, en general. Dichas ideas son recogidas en el vídeo musical, dirigido por Christopher Sweeney, estrenado en la página web de la cantante. Gracias al buen recibimiento por parte de la audiencia se ha convertido en un himno feminista por su carácter de manifiesto y su estilo provocativo y reivindicativo hacia el estatus de la mujer en la industria del disco.

El concepto desarrollado se basa en la representación del rodaje del clip en el que la cantante debe seguir las directrices de su representante para aparecer de forma sexual y afín a los cánones que se asocian con su papel como mujer pero también como objeto sexual. Así, el clip comienza en un quirófano en el que la artista se está sometiendo a una liposucción, a instancias de la discográfica -representada por el manager presente durante la intervención- para amoldarse al canon de belleza impuesto por los medios. A continuación, la cantante se une a un grupo de bailarinas y comienza a bailar con ellas en un set de rodaje en que vuelve a aparecer el representante, quien le aconseja que realice los movimientos de forma más explícita. Supone una enumeración de escenas basadas en otros vídeos musicales -como ejercicio de intertextualidad-así como en tópicos asociados con el rol atribuido a las mujeres y la ruptura de los mismos. Por ese sentido de perversión de los códigos preestablecidos y de los estereotipos de género, la cantante se presenta fregando llantas en una cocina parodiando el rol femenino y al mismo tiempo manteniendo una actitud tradicionalmente masculina fumando, bebiendo e interactuando con las bailarinas como si se tratase de un hombre, rodeada de billetes, lingotes de oro y grandes coches, en referencia a los tópicos de los raperos en sus vídeos musicales.

Los escenarios presentados son la sala de operaciones inicial, el estudio de grabación del videoclip de color dorado y sin ningún otro elemento, en el que la cantante junto con las bailarinas realizan su coreografía, una cocina en la que la cantante ejecuta su performance, un decorado neutro de color negro en el que aparecen focos y un coche y posteriormente globos plateados de gran tamaño que forman la frase: «Lily Allen has a 
baggy pussy» en alusión al vídeo musical Blurredlines -analizado anteriormente en este artículo- de Tobin Ticke. Por otra parte, los personajes que se presentan en las distintas escenas son la propia cantante desempeñando el rol de artista y realizando su performance interpretándose a sí misma, el grupo de seis bailarinas, el manager y el cirujano plástico junto a dos enfermeras quien en la escena siguiente se transforman en bailarinas. Así, los personajes componen un total de siete figuras. Por otra parte, subrayar que tanto la cantante como las bailarinas no poseen un físico acorde con el canon actual de mujeres delgadas, casi sin curvas y artificialmente perfectas.

Otros elementos importantes en el clip y con los personajes interactúan son llantas, lingotes, una cámara instantánea, billetes, un plátano, tabaco, un coche, numerosas botellas de champán, globos plateados formado una frase y altavoces, haciendo alusión a los numerosos product placement que aparecen en el vídeo musical asumiendo su naturaleza como formato publicitario. Las marcas a las que se alude son las siguientes: cámara Instax mini 90 de Fujifilm, cigarrillos E-Lites, champan Veuve Clicquot y altavoces Beats Audio. Igualmente, se hace alusión a los programas de Jimmy Kimmel Live (ABC) y Late Show with David Letterman (CBS), de la televisión norteamericana.

Este vídeo musical consta de 185 planos que combinan planos generales, medios, primeros planos y planos detalle. En los planos iniciales tomados desde una posición cenital se realiza un zoom para acercarse al rostro de la cantante mientras realiza el playback de la canción. Al comienzo del primer estribillo, la cámara recobra su verticalidad habitual, tomando planos generales de la artista junto al grupo de las bailarinas. Así, el plano comienza a abrirse en amplitud para tomar registro del escenario en el que se encuentran los personajes y en el que realizan su coreografía. A continuación se alternan primero planos con planos medios de la cantante en las distintas escenas así como planos detalles de algunos objetos que tratan de publicitarse en el clip. Las transiciones entre planos se han producido con rápidos fundidos a negro así como cortes simples.

Los sentimientos y valores que se desprenden de las imágenes del clip se relacionan con la parodia, la burla y la ironía por lo que el vídeo adquiere un sentido cómico, pero al mismo tiempo se vislumbra un trasfondo de reivindicación y de lucha por los derechos de la mujer a través de la letra de la canción y del despliegue audiovisual desarrollado en torno a ella. La parodia es el centro de este vídeo musical, acorde con la imagen anterior de la cantante dada al uso de la ironía en sus producciones. Su presencia se advierte ya en el título de la canción, ya que alude a la canción «lt's Hard out Here for a PIMP» de 2006 e interpretada por Three 6 Mafia, ganadora del Oscar a la mejor canción original por pertenecer a la banda sonora de la película Hustle \& Flow.

A través de la letra de la canción se realiza una defensa de la posición de la mujer y de su papel en la industria musical. Su discurso subraya las diferencias entre hombres y mujeres en varios ámbitos. En una pantalla de televisión aparece un videoclip en el que un grupo de bailarinas realiza una coreografía de contenido sexual basada en el twerking. En la siguiente escena, la cantante aparece en la cocina, ironizando con los roles tradicionales asociados con la mujer. La letra continúa examinando las presiones a las que se someten las mujeres en la industria del espectáculo como duras dietas para mantener un peso esquelético y las operaciones de cirugía estética para conseguir un aspecto juvenil. La letra de la canción incluye sentencias como «l suppose I should tell you what this bitch is thinking. You find me in the studio and not in the kitchen», «Don't need to shake my ass for you 'cause l've got a brain. If I told you about my sex life you'd call me a slut. Them boys be talking 'bout their bitches, no one's making a fuss», "You should probably lose some weight, 'cause we can't see your bones», «Inequality promises that it's here to stay. Always trust the injustice 'cause it's not going away». Aparece también una escena, muy explícita, en la que aparece el manager y la cantante practicando con plátanos de forma sexual. El manager parece indicar a la artista el mejor modo de hacerlo para resultar seductora ante la cámara y los espectadores. Se subrayan las diferencias entre géneros respecto a la sociedad. Con todo ello, la cantante pretende parodiar el papel masculino, especialmente de estereotipos asociados a los raperos, representados en el vídeo musical de Hip-Hop, por ello aparecen los billetes y los lingotes, los coches de lujo, entre otros objetos de ostentación así como realizando acciones tradicionalmente relacionadas con el rol de los hombre como fumar, beber alcohol o manteniendo actitudes sexuales de dominación con las bailarinas.

\subsection{La mujer aceptada: All About the Bass, Meghan Trainor}

Este vídeo musical, dirigido por Fatima Robison, tiene como base el tema "All About the Bass", interpretado por 
Meghan Trainor y compuesta por esta y Kevin Kadish como single del álbum Title de 2015. Esta canción se mantuvo en el número uno de la lista de Billboard Hot 100 en distintos países durante varias semanas y posee más de seiscientos millones de visitas en YouTube. Asimismo fue nominada a los premios Grammy como canción del año.

El concepto desarrollado se caracteriza por la sencillez, ya que en él se presenta una coreografía, creada por Charm La'Donna, realizada por la cantante junto a grupo de bailarinas sobre un fondo neutro de color rosa. La puesta en escena, basada en colores pastel y en la presencia de determinados elementos como flores y pasteles, se muestra primordial como apoyo para el mensaje que pretende transmitir la letra de la canción.

Los personajes que rodean a la cantante como agente fundamental del clip son un grupo de cuatro bailarinas que la acompañan durante su performance ejecutando su coreografía. Aparece también un chico obeso que realiza su propio baile junto a una chica muy delgada vestida con un traje de plástico. En torno a la cantante en otra escena se presenta a un chico caracterizado como el muñeco Ken, novio de Barbie, en alusión a la letra de la canción. Por último, aparecen dos niñas jugando con una casa de muñecas y posteriormente bailando. En total, diez personajes entre los que se incluye a la cantante. Estos existentes interactúan con algunos elementos sobresalientes del clip son la casa de muñecas, las muñecas de tipo Barbie, los globos, los pasteles y los dulces, el juego de té, las bicicletas y las revistas. Todos estos elementos inciden en una estética pastel, infantil y cursi.

En relación a las acciones, estas se ejecutan en cinco escenarios principales, caracterizados por la sencillez y las tonalidades pastel: el primero de ellos es un fondo rosa neutral sin ningún otro elemento en el que la cantante junto a cuatro bailarinas realiza la performance de la canción; el segundo decorado muestra una habitación en colores rosas con cenefas turquesa y una alfombra rosa fucsia en la que se han colocado sillas para los personajes femeninos anteriormente descritos; el siguiente escenario representa un dormitorio de tipo infantil en el que aparece una cama, una cómoda y una casa de muñecas con la que interactúan algunos de los personajes, principalmente las niñas; por último, la cantante realiza su performance tumbada en un suelo cubierto de telas de tul de colores pastel.

El videoclip se compone de 165 planos, iniciándose con un plano medio de la cantante quien comienza a interpretar la canción. A continuación, el plano se abre para recoger la coreografía de las bailarinas junto a la artista. Así, abundan los planos medios y primeros planes de la cantante, intercalados con planos más generales que presentan a las figuras en su totalidad, por lo que son numerosos los zooms realizados para ampliar el campo de visión. En cuanto al montaje, los distintos planos se intercalan sin transición, es decir, por corte simple, y se realizan algunos efectos relativos a la temporalidad, como la escena en la que la se presentan acciones en la habitación de la casa de muñecas a cámara rápida, dándole un efecto cómico. También se produce la división vertical de la pantalla para presentar dos imágenes de «before» y «after». Los planos de elementos como flores o muffins se intercalan a gran velocidad con aquellos en los que los personajes realizan las coreografías. El clip finaliza con un fundido a negro circular que enmarca el rostro de la cantante hasta desaparecer en el centro.

En cuanto a los valores y los sentimientos reflejados en el clip, se observa el predominio de una sensación de optimismo y fuerza, de alegría y de bienestar consigo mismo, de aceptación en consonancia con la letra de la canción y su valor como himno de los discriminados por razones físicas. Esto se refleja en extractos de la letra como los siguientes: "Yeah it's pretty clear, I ain't no size two but I can shake it, shake it like l'm supposed to do. 'Cause I got that boom boom that all the boys chase all the right junk in all the right places. I see the magazines working that photoshop, we know that shit ain't real, C'mon now, make it stop» o «You know I won't be no stick figure silicone barbie doll», evidenciando el carácter reivindicativo de la canción.

Por todo lo expuesto, este vídeo musical trata de romper con los estereotipos asociados a la mujer, en especial a los relativos a su imagen, aspecto físico y el canon de belleza establecido por los medios de comunicación de masas o las revistas de moda, entre otros. La cantante no se ajusta a las medidas físicas que se aceptan como bellas en la actualidad, por lo que su imagen, actitud y la letra de la canción adquieren un carácter de reivindicación, ruptura con lo anterior e imposición de modelos de belleza más reales. Tanto es así, que la cantante, de generosas formas, junto a sus bailarinas se opone a una chica muy delgada a la que se presenta 
de una forma ridícula, asociando a dicho personaje con valores como lo artificial, la simpleza mental y la ausencia de inteligencia.

Este videoclip se inserta en una oleada novedosa y actual que pretende la implantación de modelos de belleza femenina y modelos de belleza más ajustados a la realidad y alejados de la imagen artificial e irreal que se difunde desde los mass media. Las diferencias físicas de los sujetos se convierten así en un valor en alza y el papel de la mujer en la sociedad se diversifica a favor de la aceptación de los defectos, alejándose de idealismos imposibles de alcanzar.

\section{CONCLUSIONES}

Tras el análisis de estos cinco vídeos musicales, se observa que el papel de la mujer en el vídeo musical es doble, sujeto a su posición protagonista o secundaria. Es decir, el rol adquirido en el clip por parte de los personajes femeninos se basa en el carácter activo o pasivo de su actuación. Por esto, si la mujer es la cantante, su rol se asemeja al de diva, con un papel de reivindicación de su poder y fuerza, de su capacidad de seducción así como, en algunos casos, la asunción de roles masculinos. Sin embargo, si la mujer aparece como bailarina o en un papel secundario similar, se torna accesorio de la figura masculina, anulada como entidad independiente y sumisa al hombre. Estas afirmaciones se evidencian en los roles asumidos en los videoclips protagonizados por hombres, Don't Stop the Party y Blurred Lines, en contraposición de aquellos interpretados por mujeres en el papel de cantante, como Dirrty, Hard Out Here y All About the Bass. En los dos primeros, las bailarinas que acompañan a los artistas presentan un papel secundario, basados en la seducción y luciendo físicos ajustados a los cánones de belleza asentado en la delgadez, la juventud, grandes bustos y amplio trasero, etc. Su rol es pasivo, sumiso y de carácter accesorio respecto al hombre, al que aparecen idolatrando. Por otra parte, en aquellos clips protagonizados por mujeres, estas adoptan actitudes más activas, fuertes y dominantes, creando un nuevo perfil asociado con la diva. También asumen un papel de reivindicación, rebeldía, crítica e incluso sátira de unos valores asociados con las figuras masculinas y que la mujer tiene la necesidad de transfigurar a través del poder de su imagen. Aun así, ellas hacen igualmente uso del valor seductor del cuerpo femenino así como de su poder sexual como se observa en el videoclip de Christina Aguilera en el que la cantante explota su sexualidad, llegando también a masculinizar sus actitudes para mantener un papel dominante.

Particularizando en los estereotipos de género, específicamente en aquellos asociados a la figura femenina se observa cómo los medios convierten a la mujer en un objeto, ya que la seducción y la sensualidad se tornan como un mecanismo esencial del aparato retórico. Asimismo, se aprecian ciertos patrones en los que la mujer aparece masculinizada, transgrediendo los roles adoptados tradicionalmente por los hombres, lo que se convierte en una forma de impacto y espectáculo. Como afirman Lipovetsky y Charles (2014: 126), «la nueva permanencia de lo femenino no se nos presenta como un "residuo", sino como una reinvención de la tradición por las mujeres, un reciclaje del pasado en el orden libre de la modernidad individualista». Lo que los autores pretenden subrayar que en la presente sociedad lo femenino no se presenta como una lacra de tiempos pasados sino que las mujeres son las que realzan sus valores para actualizar los valores femeninos tradicionales. En este mismo sentido, matizan (Lipovetsky \& Charles, 2014: 127) que «con la feminización de los estudios y los empleos, con la desestabilización de los papeles y el acceso de las mujeres a puestos de responsabilidad antaño propios de los varones, aumenta la necesidad de reafirmar la identidad femenina mediante signos "ligeros" pero manifiestos", es decir, se da respuesta al uso del cuerpo por parte de la mujer en los vídeos musicales y en los medios de masas en general que tienen como objetivo reafirmar su papel femenino, diferenciándose de la figura masculina al mismo tiempo que se huye de la discriminación de género.

Las desigualdades entre hombres y mujeres deben en la actualidad desposeerse del matiz negativo siempre que se respeten los valores individuales de ambos géneros y no se llegue a la discriminación. Los medios masivos como el videoclip fomentan estas desigualdades al mismo tiempo que suponen una oportunidad de representación de los valores masculinos y femeninos. En el vídeo musical se observan roles duales por parte de la mujer, por lo que se afirman las diferencias entre estas y las figuras masculinas al mismo tiempo que se reivindica su identidad individual y colectiva como género. 


\section{REFERENCIAS BIBLIOGRÁFICAS}

Aguaded, I. \& Pérez, M.A.: "La imagen de la imagen”. Comunicar, 4 (1995), pp. 64-68.

Belmonte, J. \& Guillamón, S.: "Co-educar la mirada contra los estereotipos de género en TV". Comunicar, 31 (2008), pp. 115-120.

Berganza, M.R. \& Del-Hoyo, M.: "La mujer y el hombre en la publicidad televisiva: imágenes y estereotipos". Zer, 21 (2006), pp. 161-175

Campos-Freire, F.: La gestión de los grupos de comunicación europeos ante la agenda digital del 2020. En Salgado F. \& Martínez V.A. (Coords.) (2012): Economía de la cultura y la comunicación en la era digital . Lisboa: Media XXI.

Colás, P. \& Villaciervos, P.: "La interiorización de los estereotipos de género en jóvenes y adolescentes". Revista de Investigación Educativa, vol. 25, nº 1 (2007), pp. 35-58.

Durá, R. (1988). Los video-clips. Precedentes, orígenes y características. Valencia: Universidad Politécnica de Valencia.

González-Gabaldón, B.: “Los estereotipos como factor de socialización de género”. Comunicar, 12 (1999), pp. 79-88.

Leguizamón, J.A.: “Exploraciones musicovisuales”. Cuadernos, 17 (2001), pp. 251-269.

Lipovetsky, G. \& Charles, S. (2014). Los tiempos hipermodernos. Barcelona: Anagrama

Roncero-Palomar, R. (2008). Antivídeo: Estética e intermedialidad. Tesis doctoral inédita. Madrid: Universidad Rey Juan Carlos.

Sánchez-López, J.A.: "Basquiat y El Bosco recuperados. El mito de la culpa y la caída en imágenes de videoclip: 'Until it Sleeps', Metallica, 1996”. Boletín de Arte, 23 (2002), pp. 565-600.

Sedeño, A.M. (2008). El videoclip musical como formato audiovisual publicitario. Actas do $5^{\circ}$ Congresso da Associação Portuguesa de Ciências da Comunicação, 750-759.

Unesco (Ed.). (2004). Las tecnologías de la información y la comunicación en la formación docente. Guía de planificación. Montevideo: Trilce.

\section{BREVE SEMBLANZA DE LAAUTORA}

Jennifer Rodríguez-López es Doctora en Educación y Comunicación Audiovisual, Máster en Patrimonio Histórico y Natural y licenciada en Humanidades por la Universidad de Huelva (España). He trabajado como Técnico en Patrimonio Universitario en dicha institución onubense y he participado en un proyecto financiado por la Junta de Andalucía sobre alfabetización mediática. Actualmente formo parte del grupo de investigación Ágora y soy revisora de la revista Comunicar.

Ámbitos. Revista Internacional de Comunicación, n.29, año 2015, tercer trimestre (verano).

Recibido: 20/05/2015

Aprobado: 10/06/2015 